\title{
Enhancement of short-term retention by appetitive-reinforcer reminder treatment
}

\author{
WESLEY J. KASPROW \\ Purdue University, West Lafayette, Indiana
}

\begin{abstract}
Choice accuracy by rats in a delayed-alternation paradigm was shown to decrease over a 120 sec retention interval. The decrement in choice accuracy was reversed by presentation of the appetitive reinforcer outside of the apparatus during the retention interval. This suggests that the reinforcer served to reactivate the target spatial memory and that the short-term retention deficit in the absence of such memory reactivation was not due to a loss of information. The results are discussed with respect to recent criticisms of memory-reactivation treatments in short-term retention tasks.
\end{abstract}

In principle, associative deficits can be caused by failure of information storage at the time of acquisition, irreversible decay of information during the retention interval, or failure of information retrieval at the time of retention testing. Although it is clear that processes that occur in temporal proximity to the learning event and during the retention interval are important for later retention (e.g., McGaugh, 1966), several memory theorists have emphasized the importance of retrieval processes (e.g., Lewis, 1979; Miller, Kasprow, \& Schachtman, 1986; Spear, 1971, 1973, 1978).

A critical observation in support of retrieval-based models of memory has been the reversal of a variety of associative performance deficits through memory reactivation, that is, "reminder" treatments. A reminder treatment re-presents, prior to testing, some subset of the stimuli present during the original learning episode. It has been hypothesized that such exposure serves to stimulate further processing of the learning event so that future retrieval is facilitated (Spear, 1978). Most studies that have demonstrated the reversal of associative performance deficits have included conditions to preclude nonassociative interpretations of reminder-induced behavioral change (see Miller et al., 1986, for a recent review).

The vast majority of successful restorations of associative performance by reminder treatments have used longterm retention tasks. Few studies using animals as subjects have investigated the effect of reminder treatments on short-term retention, but those directed toward the problem have obtained positive results. Feldman and Gordon (1979) alleviated forgetting over a 90-sec retention interval in a T-maze delayed-alternation preparation using rats. In delayed alternation, an animal is initially forced

This research was partially supported by NIMH Grant MH42052. I thank Judith Schultz and Erin Hoenig for assistance in collecting the data. I am also grateful to E. John Capaldi, Ralph R. Miller, and James $H$. Neely for critically reading the initial draft of this paper. Correspondence concerning this paper should be addressed to the author, who is now at the Department of Psychology, Northern Illinois University, DeKalb, IL 60115. to one goal arm of a T-maze. Following a retention interval, the animal is given a choice run with both goal arms open. Reinforcement on the choice run is contingent upon selection of the arm opposite to that visited on the forced run. Feldman and Gordon found that delayedalternation accuracy was substantially reduced by increasing the retention interval between the forced and choice runs to $90 \mathrm{sec}$. However, a 5 -sec exposure to the forcedrun side of the maze before the choice run increased choice accuracy; that is, forgetting was apparently alleviated.

In a conceptually related study, Gordon and Feldman (1978) showed that reminder treatments could enhance the influence of an interfering memory in the delayedalternation preparation. When rats were forced to one side of the T-maze and then the other, they showed impaired ability on the choice run to alternate with respect to the most recent forced run; that is, the initial forced run seemed to interfere proactively with the memory of the second (target) forced run. Separation of the two forced runs by $120 \mathrm{sec}$ reduced this effect. Presumably, the memory of the initial forced run was weakened by the interval between forced runs; therefore, it interfered less with the memory of the target forced run at the time of the choice run. However, a 5-sec exposure to the goal arm of the initial forced run, given shortly before the second forced run, lowered accuracy on the choice run. Gordon and Feldman suggested that this spatial information served to reactivate the memory of the initial (interfering) forced run, thus causing the impairment of alternation accuracy.

Grant and Marshal (1985) have questioned whether the reminder-induced modification of short-term retention shown by Gordon and his colleagues (Gordon \& Feldman, 1978; Feldman \& Gordon, 1979) was due to changes in memory retrieval. They suggest that the spatial information from the goal-arm confinement used in the studies cited above might have been sufficient to influence alternation through relevant new learning on the reminder exposure (see also Gold \& King, 1974). That is, the task on the delayed-alternation choice run requires choosing the arm opposite the one most recently visited. An animal 
receiving a goal-arm-placement reminder treatment in delayed alternation might alternate on the basis of spatial information from the forced run, the reminder treatment, or, more likely, some combination of the two. Working with a proactive interference paradigm similar to that used by Gordon and Feldman (1978), Grant and Marshal (1985) replicated the reduction in choice accuracy resulting from an additional forced run before the target forced run, the weakening of that interference with a 60 -sec interval between the interfering and target forced runs, and reactivation of the interference effect by a reminder exposure to the goalbox shortly before the target forced run. However, they also found that the same spatial-information reminder treatment decreased alternation on control trials that omitted the initial interfering event. That is, spatial reminder alone mimicked the action of the complete interfering forcing. This tendency was weak with a 5-sec reminder exposure to the goal arm (Experiments 1 and 2) (as it was in the Gordon \& Feldman study), but increased significantly with increases in reminder exposure durations to 15 and $45 \mathrm{sec}$ (Experiment 3 ). A nonsignificant tendency for the reminder treatment on control trials to mimic a complete forced run was also present in Feldman and Gordon's (1979) study. Thus, it appears possible that the "reminder" effects that Gordon and Feldman observed could be explained by the acquisition of task-relevant new information on the reminder trials.

It has been known for decades that passive placements in spatial locations can, under some circumstances, act as surrogates for complete training trials. Seward and Levy's (1949) demonstration of "latent extinction" is just one case in point. That the influence of the reminder treatments on control trials was statistically unreliable in Gordon and Feldman's (1978; Feldman \& Gordon, 1979) studies and marginally reliable in Grant and Marshal's (1985) studies is not sufficient to dismiss consideration of the tendency because, as Grant and Marshal argue, the reminder effect on forgetting trials may represent the summative effects of weak memory of the initial forced run and weak new learning from the goal-arm placement.

For reminder effects in long-term retention, various stimuli have been used as reminder treatments. These include conditioned stimuli in isolation, unconditioned stimuli in isolation, and contextual stimuli that avoid the presentation of task-relevant information (e.g., Balaz, Gutsin, Cacheiro, \& Miller, 1982). In fact, Gordon and Mowrer (1980) obtained successful reminder effects in active avoidance by rats by using contextual-stimulus exposure that actually decreased the performance of animals not subjected to the source of forgetting (electroconvulsive shock). The only prerequisite for a stimulus presentation to work effectively as a reminder treatment would seem to be that it will have been a salient aspect of training. Training stimuli other than spatial information could perhaps serve as effective reminders in delayed alternation. To investigate the reversal of forgetting in delayed alternation by using a reminder treatment that would avoid the presentation of task-relevant information, the present study used the appetitive reinforcer presented outside of the $\mathrm{T}$-maze as a reminder stimulus in a delayed-alternation paradigm similar to that used by Feldman and Gordon (1979).

One potential difficulty in the present research was that, since the reinforcer would be present on both forced and choice runs, the appetitive reinforcer might not be effective in reactivating the memory of only the preceding forced run. That is, as a reminder stimulus, the reinforcer might reactivate the memory not only of the immediately preceding forced run, but of other runs as well. To address this potential problem, a second group of animals was trained to alternate responses in the T-maze, but these animals always encountered one type of food on the forced run and a second type of food on correct choice runs. Thus, as a unique aspect of forced runs, "forced-run food" used as a reminder stimulus might be particularly effective in reactivating the memory of only the most recent forced run. As it turned out, the appetitive reinforcer served as an effective reminder stimulus whether or not distinct food types were used for the forced and choice runs.

\section{METHOD}

\section{Subjects}

Twelve experimentally naive male albino rats purchased from a commercial supplier (Holtzman Inc., Madison, WI) served as subjects. The rats were approximately 160 days old at the start of the experiment and had free-feeding body weights of approximately $600 \mathrm{~g}$. The animals were individually housed in standard wire-mesh and sheet-metal cages in a vivarium that was maintained on a $12-\mathrm{h}$ light/12-h-dark daily cycle. The experiment was conducted during the light portion of the cycle. The animals were handled by the experimenter and acclimated to a restricted diet of $15 \mathrm{~g}$ per day of powdered Purina Lab Chow beginning 10 days before the start of the experiment. Water was freely available in the home cage

\section{Apparatus}

Training and testing occurred in a black Plexiglas T-maze with clear Plexiglas lids. All maze sections were $8.5 \mathrm{~cm}$ wide and $12.5 \mathrm{~cm}$ high. The stem of the maze was $67 \mathrm{~cm}$ long; the first $31 \mathrm{~cm}$ of this section was separated from the rest of the maze by a clear Plexiglas guillotine door and served as a startbox. Each arm of the maze was $37 \mathrm{~cm}$ long; access to the arms was controlled by clear Plexiglas guillotine doors. Each arm of the maze contained a wooden food cup at the far end. The floor of the maze consisted of parallel 0.5 -cm-diam metal rods spaced $1.25 \mathrm{~cm}$ center-to-center.

The animals spent retention intervals and intertrial intervals in a holding cage located approximately $1 \mathrm{~m}$ from the maze startbox. The holding cage was $30 \mathrm{~cm}$ long, $21.5 \mathrm{~cm}$ wide, and $21.5 \mathrm{~cm}$ high. The floor, ceiling, and rear wall of the cage were sheet metal. The front and side walls were wire mesh. The outsides of the side walls were covered with white translucent paper.

The $T$-maze and holding cage were located in a room that was illuminated by overhead fluorescent lights. A ventilation system in the room provided an ambient sound level of $65 \mathrm{~dB}(\mathrm{C})$.

\section{Procedure}

The present procedure was a modified version of that used by Feldman and Gordon (1979). On each of the 2 days immediately preceding the start of the experiment, all rats were given, in the home cage, the reinforcer to be used in delayed-alternation training, that is, five pieces each of two types of sugared cereal (Kel- 
logg's Honey Smacks and Corn Pops). Exposure to the cereal occurred approximately $1 \mathrm{~h}$ before the daily feeding. At this time, the animals were assigned randomly to one of two treatment conditions, Group Same-Food $(n=6)$ and Group Different-Food $(n=6)$.

Adaptation to the T-maze occurred on the initial 2 days of the study. Each rat was allowed to explore the entire T-maze (all doors open) twice on each day for a 5-min period. Five minutes in the holding cage intervened between exposures. During each exposure, the food cups were baited with two pieces of cereal in each. Half of the animals in Group Same-Food encountered Honey Smacks in both food cups on these exposures; the remaining Same-Food animals encountered Corn Pops. Rats in Group Different-Food found Honey Smacks in one food cup and Corn Pops in the other. The side containing each food type was reversed for each subsequent exposure.

Alternation training began on the day following completion of the adaptation phase. All animals were given a total of 18 delayedalternation training sessions. These occurred 6 days per week over the course of 3 weeks. Six trials were administered during each training session; thus, a total of 108 trials were administered to each rat. Each trial consisted of a forced run and a choice run. On the forced run, an animal was detained in the startbox for $5 \mathrm{sec}$ after placement. When the startbox door was opened, the animal was "forced" into one baited arm of the maze since the door to the opposite arm was closed. After the rat consumed the reinforcer, the animal was immediately placed in the holding cage. The doors to both arms were then opened, and the rat was returned to the startbox. (This took approximately $5 \mathrm{sec}$.) After a 5 -sec detention in the startbox, the animal was again released from the startbox and allowed to choose either arm. If the animal chose the arm opposite that to which it had most recently been forced, the rat was reinforced and the trial was concluded. If the rat chose the same arm visited on the forced run, it was not reinforced and was returned immediately to the startbox for another choice run. Choice runs were repeated in this manner until the animal alternated away from the forced-run side. Upon completion of a training trial, the animal was placed in the holding cage for a $3-\mathrm{min}$ intertrial interval. The arm to which an animal was forced (left or right) on each trial was predetermined by a pseudorandom sequence that equated for left and right turns within each training day.

During the training trials, half the animals in Group Same-Food were reinforced with two pieces of Honey Smacks; the remaining animals in this group were reinforced with two Corn Pops. Half the animals in Group Different-Food found Honey Smacks on the forced run and Corn Pops on the choice run. The remaining different-food animals were reinforced by Corn Pops and Honey Smacks on the forced run and choice run, respectively.

Retention testing began $24 \mathrm{~h}$ following the completion of the training phase, and was continued for 10 consecutive days. One each of the five trial types listed in Table 1 was administered to each subject on each day. The intertrial interval was $3 \mathrm{~min}$.

The F-0, F-30, and F-120 trial types consisted of a forced run to one arm followed by a choice run that occurred nominally 0 , 30 , or $120 \mathrm{sec}$ later, respectively. As in training, animals in Group Same-Food encountered the same type of reinforcer on the forced and choice runs. Rats in Group Different-Food encountered one type of reinforcer on the forced run and the other reinforcer on the choice run. The food type encountered on the forced runs remained constant within subjects across trials. These trials were intended to demonstrate the sensitivity of the present preparation to shortterm retention deficits.

The remaining two trial types assessed the effectiveness of exposure to the training reinforcer as a reminder treatment. F-R-30 trials were identical to F-120 trials except that $30 \mathrm{sec}$ before the choice run, the food reinforcer was given in the holding cage. For animals in both groups, the reinforcer consumed in the holding cage was the same type and amount as that consumed on the forced run. R-30 trials controlled for nonassociative effects of the reminder treatment. These trials were identical to the F-R-30 trials except that the forced run was omitted. Thus, on these trials, the animals experienced the reminder treatment but had no relevant recent memory to reactivate.

Each animal received the trial types in a different order on each day, the orders being determined by Latin squares. The left-right sequence of forced runs was pseudorandom and was equated across blocks of 2 test days.

\section{RESULTS}

Two animals from Group Different-Food were lost from the study. One of these animals died before testing, and the other failed to consistently consume the reinforcer during initial alternation training. They were not replaced.

Delayed-alternation accuracy during the various test trials for both groups of animals (collapsed across days) is depicted in Figure 1. A trial was determined to be "correct" in the R-30 condition (no forced run) if the animal chose the side opposite the one listed in the predetermined forced-run sequence. It is clear that the same- versus different-food manipulation had no effect on choice accuracy during the test phase. A preliminary $2 \times 5$ analysis of variance comparing reinforcer condition (same vs. different) and trial type (F-0 vs. F-30 vs. F-120 vs. F-R-30 vs. R-30) indicated a significant effect of trial type $[F(4,32)=8.40, p<.05]$ but no effect of reinforcer condition and no interaction of this variable with trial type $(F \mathrm{~s}<1)$. Therefore, the reinforcer condition variable was ignored in subsequent analyses.

Statistical differences among trial types were assessed using critical difference tests (Lindquist, 1956), with $\alpha=.05$. The three leftmost pairs of bars in Figure 1 demonstrate forgetting; the animals maintained a high degree of accuracy in alternation on the F- 0 trials, whereas a 30-sec retention interval on the F-30 trial produced a marginally significant $(.05<p<.10)$ reduction in accuracy, and accuracy was significantly reduced on the F-120 trials relative to the F- 0 and F- 30 conditions. Thus, the present preparation was sensitive to short-term forgetting.

Data from the F-R-30 condition show that the reminder treatment was effective. The reminder treatment (reinforcer alone in the holding cage) given during a complete alternation trial (F-R-30 trials) significantly increased delayed-alternation accuracy relative to the F-120 trials. Performance on the F-R-30 trials was not different from that on the F-30 trials, but was significantly less accurate than performance on the F-0 trials. Importantly, the reminder treatment given on trials in which the forced run was omitted (R-30 trials) had no enhancing effect on accuracy. Performance on R-30 trials was significantly worse than performance on F-R-30 trials. Moreover, there was a nonsignificant tendency toward below-chance performance on the R-30 trials. Thus, the performanceenhancing effect of the reminder treatment was specific 


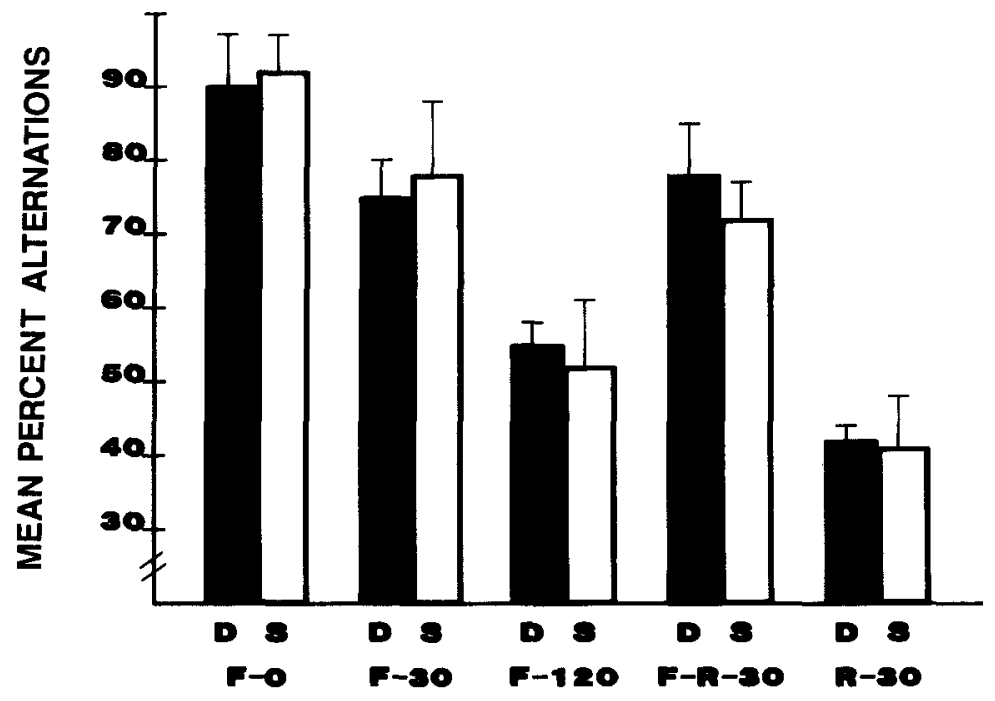

Figure 1. Mean percent alternations (collapsed over 10 test days) for each trial type. Solid bars indicate the different-food condition; open bars indicate the samefood condition. Brackets indicate one standard error of the mean.

to the trials that contained relevant information to be reactivated, that is, a forced run.

\section{DISCUSSION}

The present research demonstrated that the appetitive reinforcer used in the delayed-alternation preparation can serve as an effective reminder treatment, that is, it can reverse the deficit in choice accuracy caused by a 120 sec retention interval (F-120 vs. F-R-30 conditions). Moreover, enhancement of choice accuracy was not seen on trials in which the reminder treatment was given but the target forcing was omitted (R-30 condition). It is virtually impossible to conceptualize how presentation of the food reinforcer in the holding cage might provide information that would guide choice behavior in the T-maze as the new-learning hypothesis (Gold \& King, 1974; Grant \& Marshal, 1985) suggests. The goal-arm-placement reminder treatment used by Gordon and Feldman (1978), Feldman and Gordon (1979), and Grant and Marshal (1985) may offer an opportunity for task-relevant new learning on the reminder trial, especially when the goalarm placement is of long duration (Grant \& Marshal, 1985, Experiment 3). However, the present results argue

Table 1

Sequence of Events in Each Trial Type

\begin{tabular}{lccc} 
& \multicolumn{3}{c}{ Seconds Before Choice Run } \\
\cline { 2 - 4 } Trial & 120 & 30 & 0 \\
\hline F-0 & & & FR \\
F-30 & FR & \\
F-120 & FR & RT & \\
F-R-30 & FR & RT & \\
R-30 & &
\end{tabular}

Note-FR $=$ forced run; $\mathrm{RT}=$ reminder treatment. that such new learning is not necessary for demonstration of the reminder effect.

The nondifferential effectiveness of the reinforcer as a reminder treatment in the same-food and different-food conditions was somewhat unexpected. It was hypothesized that the different-food group would show a larger reminder effect, because the food used as a reminder stimulus was experienced only on the forced runs. However, the present research had no independent assessment of whether animals actually perceived the different food types as being qualitatively distinct. The choice of reinforcers in the present research was in part based on the ability of rats to discriminate between the two cereal types in pattern learning in a runway (E. J. Capaldi, personal communication, January 1986). Without independent evidence that Group Different-Food could respond to the reinforcers differentially in the present situation, speculation about the equal reminder effect observed across groups is pointless.

The present findings are consistent with the view that retrieval failure contributes to forgetting in delayed alternation. This view suggests that each run in the T-maze establishes a memory for that event. Accuracy on a choice run is dependent upon retrieval of the memory of the most recent forced run, which in turn is presumably dependent upon the similarity of cues present on the forced and choice runs. Re-presentation of a salient cue from that forced run (in the present case, the reinforcer) is hypothesized to facilitate retrieval of the memory for that run. Demonstration of the reminder effect in a short-term retention paradigm such as delayed alternation lends support to the view that many associative performance failures are governed by the retrievability of a memory and not by the age of the memory per se. Thus, forgetting in a short-term retention task may not be qualitatively 
different from forgetting that occurs over long retention intervals. Retrieval failure can occur over very short retention intervals (see also Miller, 1982).

While the present reminder effect is fully explained in terms of retrieval failure, Grant (1986) has proposed a working-memory model of short-term retention that makes similar predictions concerning the effectiveness of reminder treatments. In Grant's view, all forced runs on delayed-alternation trials are not permanently encoded in memory, as models emphasizing retrieval suggest. Rather, a given forced run might simply serve to activate a permanent representation of the spatial location (left side vs. right side) that was acquired early in training. In Grant's model, for successful choice run performance, this active memory must be rehearsed during the retention interval. Forgetting over the retention interval is due to decay of the active memory as a result of the cessation of rehearsal. Grant explicitly argues against the importance of memory retrieval occurring at the time of the choice run. Reminder treatments are effective, according to Grant, because they serve to reinitiate the rehearsal process during the retention interval. That is, the presentation of one attribute of the active memory serves to renew rehearsal of the complete episode, increasing its effective strength at the time of the choice run relative to a no-reminder condition.

It is clear that both retrieval-based models and Grant's rehearsal-based model hinge on the view that presentation of one attribute from a target event can serve to promote performance based on the entire event. The present results demonstrate that the reinforcer used in training is a salient attribute for this purpose. The question to be answered is whether enhanced choice performance in the present study was due to the reactivation of an inactive memory or to the prolongation of rehearsal of an active memory. Unfortunately, these two positions cannot be distinguished solely by observation of reminder effects in short-term retention tasks. However, the retrieval interpretation can explain reversal of forgetting by reminder not only in short-term retention preparations where it is unclear whether or not the target memory remains active, but also in long-term retention preparations where memories clearly become inactive due, for example, to a retention interval of weeks (Deweer, Sara, \& Hars, 1980 ) or to electroconvulsive shock (Miller, Ott, Berk, $\&$ Springer, 1974). Thus, the notion that reminder treatments reactivate inactive memories has considerably more generality than the notion that reminders prolong the rehearsal of active memories.

\section{REFERENCES}

Balaz, M. A., Gustin, P., Cacheiro, H., \& Miller, R. R. (1982). Blocking as a retrieval failure: Reactivation of associations to a blocked stimulus. Quarterly Journal of Experimental Psychology, 34B, 99-113.

Deweer, B., Sara, S. J., \& Hars, B. (1980). Contextual cues and memory retrieval in rats: Alleviation of forgetting by a pretest exposure to background stimuli. Animal Learning \& Behavior, 8 , 265-272.

Feldman, D. T., \& Gordon, W. C. (1979). The alleviation of shortterm retention deficits with reactivation. Learning \& Motivation, 10, 198-210.

GolD, P. E., \& King, R. A. (1974). Retrograde amnesia: Storage failure versus retrieval failure. Psychological Review, 81, 465-469.

GoRdon, W. C., \& Feldman, D. T. (1978). Reactivation-induced interference in a short-term retention paradigm. Learning \& Motivation, 9, 164-178.

Gordon, W. C., \& Mowrer, R. R. (1980). An extinction trial as a reminder treatment following electroconvulsive shock. Animal Learning \& Behavior, 8, 363-367.

GRANT, D. S. (1986). Delayed alternation and short-term memory in the rat. In D. F. Kendrick, M. E. Rilling, \& M. R. Denny (Eds.), Theories of animal memory (pp. 153-171). Hillsdale, NJ: Erlbaum.

Grant, D. S. , \& MARSHAL, L. M. (1985). Short-term retention in rats: The effect of goal-arm confinement on delayed alternation in rats. Animal Learning \& Behavior, 13, 109-115.

LEWIS, D. J. (1979). Psychobiology of active and inactive memory. Psychological Bulletin, 86, 1054-1083.

LiNDQUisT, E. F. (1956). Design and analysis of experiments in psychology and education. Boston: Houghton-Mifflin.

McGaugh, J. L. (1966). Time-dependent processes in memory storage. Science, 153, 1351-1358.

Miller, R. R. (1982). Effects of intertrial reinstatement of training stimuli on complex maze learning in rats: Evidence that "acquisition"' curves reflect more than acquisition. Journal of Experimental Psychology: Animal Behavior Processes, 8, 86-109.

Miller, R. R., Kasprow, W. J., \& Schachtman, T. R. (1986) Retrieval variability: Sources and consequences. American Journal of Psychology, 99, 145-218.

Miller, R. R., Ott, C. A., Berk, A. M., \& Springer, A. D. (1974). Appetitive memory restoration after electroconvulsive shock in the rat. Journal of Comparative \& Physiological Psychology, 87, 717-723.

Seward, J. P., \& LeVY, H. (1949). Latent extinction: Sign learning as a factor in extinction. Journal of Experimental Psychology, 39, 660-668.

SPEAR, N. E. (1971). Forgetting as retrieval failure. In W. K. Honig \& P. H. R. James (Eds.), Animal memory (pp. 45-109). New York: Academic Press.

SPEAR, N. E. (1973). Retrieval of memory in animals. Psychological Review, 80, 163-194.

SPEAR, N. E. (1978). The processing of memories: Forgetting and retention. Hillsdale, NJ: Erlbaum.

(Manuscript received December 16, 1986; revision accepted for publication May 1, 1987.) 